\title{
Unass
}

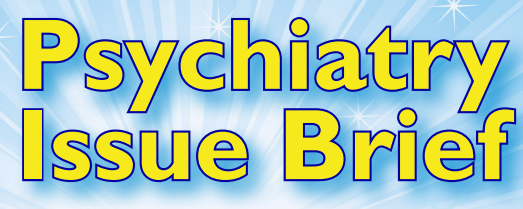

Systems and Psychosocial

\section{Using Risk Assessment and Risk-Needs-Responsivity Principles in Juvenile Justice}

Gina M.Vincent, PhD

$\mathrm{T}$ There is an emerging consensus in the juvenile justice field that punitive sanctions alone do not have a significant effect on reducing juvenile reoffending (Gatti et al., 2009). In fact, research has found that with some youths, any exposure to the juvenile justice system (e.g. community service or probation) can actually increase their chances of offending again (Models for Change Research Initiative, 2011). It has also been found that the severity of the first offense is not a significant indicator of future patterns of offending (Mulvey et al., 2010), and that the majority of low-risk youth are unlikely to reoffend even with little to no intervention (Lipsey, 2009). Given the high cost of confinement of juvenile offenders, it would benefit both juveniles and juvenile justice agencies to sort juvenile offenders by risk, to divert low risk offenders away from the juvenile justice system as often as possible, and to focus on services to high risk offenders.

Sorting juvenile offenders by risk requires valid risk assessment instruments, critical tools for facilitating matching the right services to the right youth at the right time. Juvenile justice systems need to consider risk in conjunction with juveniles' mental health, to ensure that appropriate services are provided. However, such problems should not be treated in isolation; they must be treated along with the other risk factors.

\section{Risk Assessment Tools}

Validated and comprehensive risk assessment tools can assess a youth's likelihood to reoffend, and suggest a proper level of intervention specifically tailored for that individual. Probation officers and other non-clinicians who use these tools must be well-trained in their use. There are different risk assessment tools available, many of which have demonstrated a reasonable level of accuracy in determining a youth's risk to reoffend. A validated risk assessment can guide intervention planning by determining what areas of the youth's life can be changed in order to reduce the likelihood of reoffending. In addition, risk assessment can offer a standardized method of important

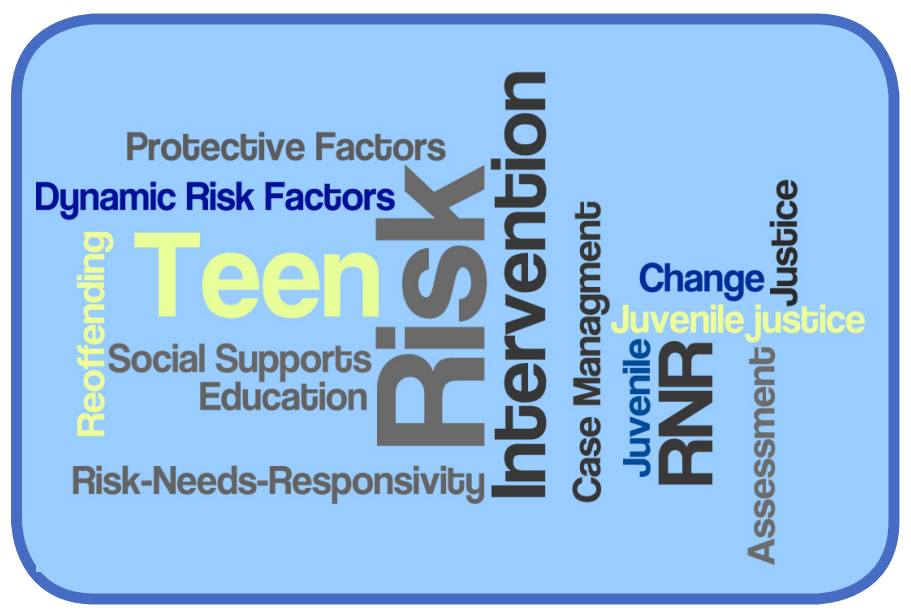

data collection to plan resource allocation and chart the overall progress of the youths.

A risk assessment tool is designed to help answer two questions:

- Is this individual at a relatively low or relatively high risk for reoffending or engaging in violent behavior?

- What risk factors are most likely to be driving this individual's offending or violent behavior?

A risk factor is anything that increases the chance that an individual will reoffend. There are two types of risk factors that are used to measure risk - static risk factors that do not change and dynamic risk factors (often referred to as a youth's criminogenic needs), which can change and be targets for intervention. Both types of risk factors must be measured to accurately access a youth's risk for reoffending.

Lipsey and Derzon (1998) offer some examples of static risk factors:

- violent behavior initiated at an early age;

- first offense or contact with the law at an early age;

- first substance use documented at an early age;

- history of violence and aggression/delinquent activity (frequency and severity); and

- current or past parental/familial criminal activity. 
Dynamic risk factors include:

- antisocial attitudes/orientation (e.g., aggressive behavior, callousness);

- disruptive behavior problems/personality traits;

- family dynamics/parenting (e.g., poor parental management);

- history of and/or a current substance abuse problem;

- poor school achievement; and

- negative peer associations.

Protective factors can buffer some risk factors, and are important to encourage an approach focused on strengths as well as risk. A protective factor must be at an above average or extraordinary level to be considered a buffer to risk. Protective factors include, but are not limited to:

- easy temperament;

- highly supportive social supports; and

- strong commitment to education (Turner et al., 2007).

Risk assessment instruments are important for identifying individuals who are most versus least likely to commit new delinquent offense or general violent acts. These instruments are not designed to:

- tell the user exactly what course of action should be taken (this requires training about how to use risk assessment information);

- identify risk for sexual reoffending (which requires special sex offense-risk assessment instruments);

- provide assessment of mental health;

- dictate legal decisions; and

- identify those who are unlikely to appear for court, unless the instrument was designed for this purpose (Vincent et al., 2012b).

\section{Risk-Needs-Responsivity (RNR) Principles}

Adoption of a risk assessment tool is unlikely to make much difference in the handling of young offenders unless it is paired with a case management approach that guides how the risk assessment should be used in case processing. Risk-Needs-Responsivity (RNR) is a well-tested case management approach that, if implemented well, can lead to better outcomes for individuals involved in the justice system (Andrews \& Bonta, 2010). The RNR approach suggests that any formal processing and case management of youth should be commensurate with a youth's level of risk for reoffending and should address the youth's specific dynamic risk factors. The basic RNR principles are:

- risk: match the intensity of the interventions to the risk level;
- need: identify treatments that target the individual's specific criminogenic needs (dynamic risk factors); and

- responsivity: select services that address the youth's unique characteristics (e.g., lack of fluency in English, a learning disability, readiness for change, or a mental illness) that may affect responsiveness to treatment.

Responsivity factors are usually non-criminogenic needs that would not be appropriate to include in a total risk score, but are important to consider for intervention planning. Responsivity factors are personal characteristics of a youth and of his/her individual circumstances that positively or negatively impact the youth's ability and motivation to engage in certain interventions.

The use of professional discretion is also a vital part of RNR because after the probation officer has reviewed the risk, needs, and responsivity considerations as they apply to a particular youth, it is sometimes appropriate for decisions about case planning to be made on the basis of good professional judgments, not merely "scores." Youth risk and needs must be weighed alongside legal, ethical, humanitarian, cost-efficiency, and service availability factors. When services are matched to a youth's level of risk, the youth's chance of reoffending is lower (Vieira et al., 2009; Peterson-Badali et al., 2015).

Implementing risk assessment with RNR principles can conserve resources for juvenile justice systems and improve outcomes for youth while still protecting public safety. However, the impact of risk assessment will ultimately be based on how well it is implemented and a site's individual characteristics (Vincent et al., 2012a). Quality implementation, quality assurance, and buy-in from stakeholders are all crucial to successfully implement risk assessment tools and principles in juvenile systems settings.

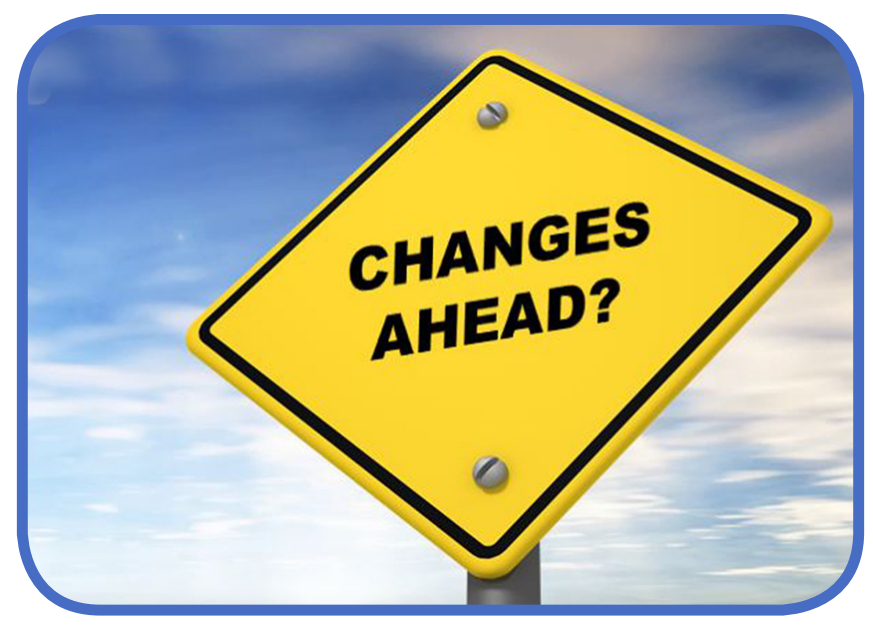

This is a product of Psychiatry Information in Brief. An electronic copy of this issue with full references can be found at http://escholarship.umassmed.edu/pib/vol13/iss2/1 


\section{References}

Andrews, D. A., \& Bonta, J. (2010). Rehabilitating criminal justice policy and practice, Psychology, Public Policy, and Law, 16,(1), 39-55. doi: $10.1037 / \mathrm{a} 0018362$

Gatti, U., Tremblay, R. E., \& Vitaro, F. (2009). Iatrogenic effect of juvenile justice. Journal of Child Psychology and Psychiatry, 50(8), 991998.

Lipsey, M. W. (2009). The primary factors that characterize effective interventions with juvenile offenders: A meta-analytic overview. Victims \& Offenders, 4(2), 124-147. doi:10.1080/15564880802612573

Lipsey, M. W., \& Derzon, J. H. (1998). Predictors of violent or serious delinquency in adolescence and early adulthood: A synthesis of longitudinal research. In R. Loeber \& D. P. Farrington (Eds.), Serious \& violent juvenile offenders: Risk factors and successful interventions (pp. 86-105). Thousand Oaks, CA: Sage Publications, Inc.

Models for Change Research Initiative. (2011). Knowledge brief: Can risk assessment improve juvenile justice practices? Retrieved from: http://www.modelsforchange.net/publications/313

Mulvey, E. P., Steinberg, L., Piquero, A. R., Besana, M., Fagan, J., Schubert, C. et al. (2010). Trajectories of desistance and continuity in antisocial behavior following court adjudication among serious adolescent offender. Development and Psychopathology, 22(2), 453-475. doi:10.1017/S0954579410000179

Peterson-Badali, M., Skilling, T., \& Hoqanee, Z. (2015). Examining implementation of risk assessment in case management for youth in the justice system. Criminal Justice and Behavior, 42(3), 304-320. doi:10.1177/0093854814549595

Turner, M. G., Hartman, J. L., Exum, M. L., \& Cullen, F. T. (2007). Examining the cumulative effects of protective factors: Resiliency among a national sample of high-risk youths. Journal of Offender Rehabilitation, 46(1-2), 81-111. doi:10.1080/10509670802071535

Vieira, T. A., Skilling, T. A., \& Peterson-Badali, M. (2009). Matching court-ordered services with treatment needs. Criminal Justice and Behavior, 36(4), 385-401. doi:10.1177/0093854808331249

Vincent, G. M., Guy, L. S., Gershenson, B. G., \& McCabe, P. (2012a). Does risk assessment make a difference? Results of implementing the SAVRY in juvenile probation. Behavioral Sciences \& the Law, 30(4), 487-505. doi:10.1002/bsl.2014

Vincent, G. M., Guy, L. S., \& Grisso, T. (2012b). Risk assessment in juvenile justice: A guidebook for implementation Chicago, IL: John D. and Catherine T. MacArthur Foundation. Retrieved from: http://escholarship.umassmed.edu/cgi/viewcontent. cgi?article $=1601 \&$ context $=$ psych_cmhsr 